Available online on 15.03 .2015 at http://jddtonline.info
Journal of Drug Delivery and Therapeutics
Open access to Pharmaceutical and Medical research
(c) 2015, publisher and licensee JDDT, This is an Open Access article which permits unrestricted noncommercial use, provided the original
work is properly cited

RESEARCHARTICLE

\title{
ASSESSMENT OF GMP COMPLIANCE IN WATER TREATMENT SYSTEMS OF PHARMACEUTICAL INDUSTRIES IN ETHIOPIA
}

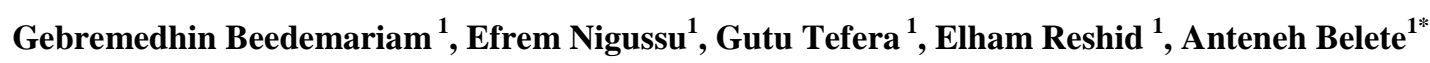 \\ ${ }^{1}$ Department of Pharmaceutics and Social Pharmacy, School of Pharmacy, College of Health Sciences, Addis Ababa \\ University, P.O.Box 1176, Addis Ababa, Ethiopia
}

Received 07 Jan 2015; Review Completed 12 Feb 2015; Accepted 13 March 2015, Available online 15 march 2015

\begin{abstract}
Water is widely used as a raw material, ingredient, and solvent in the processing, formulation, and manufacture of pharmaceutical products, and assessing its quality is of paramount importance. To the best of the authors' knowledge, there hasn't been any baseline assessment made with regard to the implementation status of Good Manufacturing Practices (GMP) principles in water treatment systems of pharmaceutical industries in Ethiopia. Hence, to assess the level of compliance to GMP in water treatment systems of pharmaceutical industries in Ethiopia, a national survey was conducted in all pharmaceutical industries of the country. Data were collected by employing quantitative and qualitative methods. Self-administered questionnaires were distributed to nine pharmaceutical industries and the response rate was $8(88.5 \%)$. According to the results, none of the industries had an influent and effluent total organic carbon monitoring system. Among the available storage tanks for purified water and water for injection, 7 (87.5\%) of them were of a sanitary material. However, in 4 (50\%) industries pipes were not made of sanitary material, purified water was not kept circulating at $70-80{ }^{\circ} \mathrm{C}$ and there were dead legs in the water lines. The validation results were investigated and corrective action was taken only in $1(12.5 \%)$ of the industries. The compliance of the water treatment systems of most of the industries to WHO GMP principles was found to be below the standard in many aspects. Therefore, it is recommended that the industries should exert maximum efforts to comply with GMP principles.
\end{abstract}

Keywords: Good manufacturing practices, water treatment system, pharmaceutical industry, Ethiopia, pharmaceutical water

\section{INTRODUCTION}

Water is the most widely used substance, raw material or starting material in the production, processing and formulation of pharmaceutical products. It has unique chemical properties due to its polarity and hydrogen bonds. It is capable of dissolving or suspending many different compounds including contaminants that may represent hazards themselves or that are able to react with intended product substances, resulting in hazards to health (WHO, 2006). Therefore, there is no pure water in nature, as it can contain unacceptable contaminants including inorganic compounds, organic compounds, solids, gases, and microorganisms (WHO, 2005).

Pharmaceutical water treatment requires removing these contaminants from municipal drinking water to meet pharmacopoeial standards (Khutia et al., 2010). Different grades of water quality are required depending on the route of administration of different pharmaceutical products (WHO, 2006). But, water used as an ingredient in the formulation of pharmaceutical products must be either of the Purified Water (PW) type or must be Water for Injections (WFI). Both share similar specifications when it comes to chemical purity but differ with their microbial contamination allowed, which is measured by colony count and by endotoxin level (Khutia et al., 2010).
Unlike other products and process ingredients, Water for Pharmaceutical Use (WPU) is usually drawn from a system on demand, and is not subject to testing and batch or lot release before use. Assurance of quality to meet the on-demand expectation is, therefore, essential. Additionally, certain microbiological tests may require incubation periods and, therefore, the results are likely to lag the water use. Control of the microbiological quality of WPU is a high priority. Avoiding biological contamination in water treatment system components is no less important than avoidance of their proliferation in storage and distribution. Therefore, control of the quality of water throughout the treatment, storage and distribution processes, including microbiological and chemical quality, is a major concern which needs complying with Good Manufacturing Practices (GMP) (WHO, 2005).

* Corresponding Author: Anteneh Belete

Department of Pharmaceutics and Social Pharmacy, School of Pharmacy, College of Health Sciences, Addis Ababa University, P.O.Box 1176, Addis Ababa, Ethiopia E-mail: antbeletes@yahoo.com Tel: (+) 251-911-684826 
WHO defines GMP as "that part of quality assurance which ensures that products are consistently produced and controlled to the quality standards appropriate to their intended use and as required by the marketing authorization" (WHO, 2003). GMP covers all aspects of the manufacturing process including: validated critical manufacturing steps; suitable premises, storage, transport; qualified and trained production and quality control personnel; adequate laboratory facilities; approved written procedures and instructions; records to show all steps of defined procedures taken; full traceability of a product through batch processing records and distribution records; and systems for recall and investigation of complaints (WHO, 1997). GMP regulations require a quality approach to manufacturing, enabling companies to minimize or eliminate cases of contamination, mix ups, or any other errors (Ziegler and Medgyesi, 2012).

This study attempts to investigate the status of the water treatment systems of pharmaceutical manufacturing industries in Ethiopia regarding compliance to GMP principles. This will allow for critical evaluation of the GMP status in order to identify gaps and design appropriate interventions.

\section{METHODS}

\section{Study design and area}

In 1993, there was only one local pharmaceutical manufacturing plant in Ethiopia named Ethiopian Pharmaceutical Manufacturing Factory which was owned by the government. Currently however drug production is being undertaken by thirteen local pharmaceutical manufacturing plants: One government owned, eleven private (not affiliated with multinationals) and one private (affiliated with multinational). Three of the factories are engaged in medical supplies production, one on empty gelatin capsule production and nine on complete product formulation using imported raw materials. However, only one of them has a certificate of competence from the Ethiopian Food Medicine and Healthcare Administration and Control Authority (FMHACA, 2012).

The survey was conducted to assess the implementation of GMP principles for water treatment systems in all 9 pharmaceutical industries that are engaged in manufacturing of finished pharmaceutical products. The survey was done on professionals working either as technical managers or production managers of the industries. The survey employed both qualitative and quantitative data collection methods. The two approaches were arranged to complement each other and data were collected between March and May 2013. Quantitative data of the professionals working in the water treatment section were collected using a structured questionnaire adopted from WHO minimum GMP requirement for pharmaceutical water systems (WHO, 2010) while a semi-structured interview guide with flexible probing technique was used for the indepth interview.

\section{Data Analysis}

After data collection, each checklist was checked for completeness and codes were given during data collection. Data entry for the survey was done using EPI info version 7 and analyzed using SPSS version 20. Furthermore, data cleaning was performed to check missed values and any inconsistencies before the data were analyzed. Descriptive statistics was used to calculate proportions and means of respondents. Transcription of qualitative data was done immediately after data collection and analysis was handled manually. The data was analyzed using thematic analysis approach.

\section{Ethical Clearance}

Ethical clearance was obtained from the Ethics Review Board of the School of Pharmacy, College of Health Sciences, Addis Ababa University and permission was then granted from all pharmaceutical industries included in the study. Participants were provided with information regarding the purpose of the study and what is expected from them. They were informed that participation is voluntary and withdrawal from the study at any point is possible. Participants were assured anonymity and that their answers will remain confidential. They were also reassured that the report of the findings will not identify them and only the aggregate data will be reported. Finally informed consent was received from every participant.

\section{RESULTS AND DISCUSSION}

\section{General Overview}

Self-administered questionnaires were distributed to all nine pharmaceutical industries and eight of them were willing to respond, with a response rate of $88.5 \%$. Four of the participants were production managers, three of them were Quality Assurance and Quality Control (QA/QC) managers and one of them was factory manager. Their working experience in pharmaceutical industry ranged from $5-22$ years with an average of 10.15 years of experience $(\mathrm{SD}=6.6)$. Four of them had Bachelor of Pharmacy while three of them had Master of Science in Pharmaceutical Sciences, and one of the respondents had Bachelor of Science in Chemistry.

Four $(66.7 \%)$ of industries claimed to be GMP certified. As shown in Table 1, all of the industries had periodic cleaning and sanitization program for water lines and hoses with adequate quality of feed water. Majority $(87.5 \%)$ of the industries had preventive maintenance programs but $3(37.5 \%)$ of them did not follow proper frequency of maintenance program. The study also showed that more than three fourth $(85.7 \%)$ of the industries had frequent sanitization program with hot water after intervention for maintenance or modification and $7(87.5 \%)$ industry had no periodic integrity tests for the filters used in distillation system (Table 1).

Standards recommend that during a water system validation, consideration must be given to the quality and seasonal variation of the feed water. Moreover, schedule of routine monitoring is the best way to ensure a membrane system is operating under optimal conditions (Pahwa, 2010). In line with this standard, the present study indicated that all of the pharmaceutical industries had adequate quality of feed water with 
Table 1: Distribution of items indicating general overview of water treatment systems of pharmaceutical industries in Ethiopia, $2013(\mathrm{~N}=8)$.

\begin{tabular}{|c|c|c|c|}
\hline \multirow[b]{2}{*}{ Items } & \multicolumn{3}{|c|}{ Response } \\
\hline & Yes; N (\%) & No; $N(\%)$ & $\begin{array}{l}\text { Not Applicable; } \mathbf{N} \\
(\%)\end{array}$ \\
\hline Availability of GMP certificate & $4(66.7)$ & $2(33.3)$ & - \\
\hline Schematic drawing representing the water system was shown & $7(87.5)$ & $1(12.5)$ & - \\
\hline Continuous supply of source of water & $8(100)$ & - & - \\
\hline Presence of raw water storage tank & $7(87.5)$ & $1(12.5)$ & - \\
\hline $\begin{array}{l}\text { Presence of preventive maintenance program that includes } \\
\text { the water system }\end{array}$ & $7(87.5)$ & $1(12.5)$ & - \\
\hline $\begin{array}{l}\text { Presence of periodic cleaning and sanitization program for } \\
\text { water lines and hoses }\end{array}$ & $8(100)$ & - & - \\
\hline Maintenance program was of a proper frequency & $5(62.5)$ & $2(25.5)$ & $1(12.5)$ \\
\hline $\begin{array}{l}\text { Analysis was established by current editions of official } \\
\text { pharmacopoeias }\end{array}$ & $8(100)$ & - & - \\
\hline $\begin{array}{l}\text { There was frequent sanitization program with hot water after } \\
\text { intervention for maintenance or modification of equipments }\end{array}$ & $6(85.7)$ & $1(14.3)$ & - \\
\hline Quality of feed water was adequate & $8(100)$ & - & - \\
\hline Presence of hydrophobic vent filter & $5(62.5)$ & $2(25)$ & $1(12.5)$ \\
\hline Periodic integrity tests for hydrophobic vent filter & $1(14.3)$ & $4(57.1)$ & $2(28.6)$ \\
\hline $\begin{array}{l}\text { Presence of hydrophobic vent absolute filter in the } \\
\text { distillation system }\end{array}$ & $5(62.5)$ & $3(37.5)$ & - \\
\hline $\begin{array}{l}\text { Periodic integrity tests for the filters used in distillation } \\
\text { system }\end{array}$ & $1(12.5)$ & $4(50)$ & $3(37.5)$ \\
\hline
\end{tabular}

\section{Water Treatment Approaches and Monitoring Systems}

The study revealed that three-fourth $(75.0 \%)$ of the industries had a system to remove chlorine. As the raw water must be free from oxidation media, dechlorination must be carried out through the use of activated charcoal (AC) filters or sodium bisulfite (Gronwald, 2012). Nevertheless, this system was absent in two $(25 \%)$ of the industries. Furthermore, none of the industries had an influent and effluent Total Organic Carbon (TOC) monitoring system of the AC filter system (Nally, 2007). Another way of monitoring the efficiency of the AC filter is through organic adsorption capacity verification systems (Nally, 2007) which was applicable only in three $(35.7 \%)$ of the industries. Since adsorption capacity refers to the AC filter efficiency to adsorb the organic impurities, decreased adsorption capacity shows saturation of the filter bed by organic impurities which leads to increased TOC level. Therefore, there should be frequent replacement of the carbon beds to maintain water quality. The study also indicated that there were no organic adsorption capacity verification systems in $5(62.5 \%)$ of the industries and only $2(28.6 \%)$ industries have undertaken frequent replacement of carbon beds for AC filter (Table 2).
To achieve the desired degree of water purification, water is further treated by ion exchange (IX) resin or Reverse Osmosis (RO) after carbon filtration (VWS, 2005). According to the results of this study, 5 (62.5\%) industries comply with the GMP principle of having frequent IX resin regeneration. Among the industries possessing IX treatment method, only 2 (25.0\%) industries constitute subsequent RO treatment system even if it is a very cost-effective technology for the removal of the majority of impurities due to its exceptional purifying efficiency.

To produce WFI, distillation is the only final purification step as part of the specification of the WFI, declared by the International Pharmacopoeia and the European Pharmacopoeia (EMEA, 2003). In consistent with this, $5(62.5 \%)$ industries producing WFI use distillation system, of which, only $1(12.5 \%)$ industry has periodic integrity tests for the filters used in the distillation system. This lack of the integrity test may have its own impact on the quality of water used for production of parenteral products as the integrity test is one of the most important monitoring systems for WFI. If the filter integrity test fails, the sterile filtration process must be rejected (Agalloco and Akers, 2008). 
Table 2: Distribution of items indicating water treatment approaches and monitoring systems of the pharmaceutical manufacturing industries in Ethiopia, $2013(\mathrm{~N}=8)$.

\begin{tabular}{|c|c|c|c|}
\hline \multirow{2}{*}{ Items } & \multicolumn{3}{|c|}{ Response } \\
\hline & Yes; N (\%) & No; $N(\%)$ & $\mathbf{N A} ; \mathbf{N}(\%)$ \\
\hline Presence of a system to remove chlorine & $6(75)$ & $1(12.5)$ & $1(12.5)$ \\
\hline Verification of organic adsorption capacity & $3(35.7)$ & $3(37.5)$ & $2(25)$ \\
\hline Influent and effluent TOC monitoring system & - & $6(75)$ & $2(25)$ \\
\hline Frequent replacement of carbon beds & $2(28.6)$ & $4(57.1)$ & $1(14.3)$ \\
\hline Validated frequency for regeneration of IX resin & $5(62.5)$ & $3(37.5)$ & - \\
\hline Presence of reverse osmosis system & $2(25)$ & $1(12.5)$ & $5(62.5)$ \\
\hline $\begin{array}{l}\text { Adequacy of the concentration of the sanitizing chemical at all } \\
\text { surfaces }\end{array}$ & $3(42.9)$ & $1(14.3)$ & $3(42.9)$ \\
\hline Frequent chemical sanitization approach & $4(57.1)$ & $1(14.3)$ & $2(28.6)$ \\
\hline Availability of SOP for sampling all types of produced water & $8(100)$ & - & - \\
\hline $\begin{array}{l}\text { Sampling procedure including validated frequency and } \\
\text { sampling points }\end{array}$ & $5(62.5)$ & $3(37.5)$ & - \\
\hline Sampling point rotation & $5(62.5)$ & $3(37.5)$ & - \\
\hline $\begin{array}{l}\text { Availability of automatic system to prevent use of water when } \\
\text { it is out of specifications }\end{array}$ & $4(50)$ & $4(50)$ & - \\
\hline Online monitoring system & $7(87.5)$ & $1(12.5)$ & - \\
\hline Offline monitoring system & $8(100)$ & - & - \\
\hline $\begin{array}{l}\text { Action limit of PW and WFI is no more than } 100 \mathrm{cfu} / \mathrm{mL} \text { and } \\
10 \mathrm{cfu} / 100 \mathrm{~mL}\end{array}$ & $5(62.5)$ & - & $3(37.5)$ \\
\hline $\begin{array}{l}\text { When the action limit is exceeded, an investigation was always } \\
\text { undertaken to ensure quality of the batches of product made } \\
\text { with that water according to OOS plan }\end{array}$ & $5(62.5)$ & - & $3(37.5)$ \\
\hline
\end{tabular}

According to the WHO, monitoring systems of the water treatment systems should include a combination of online and offline monitoring systems (WHO, 2005). The results of the study show that $7(87.5 \%)$ of the industries have online monitoring system while 8 $(100 \%)$ of them have offline monitoring system (Table 2). In addition, all of the industries, 8 (100\%) mentioned that they have Standard Operating Procedures (SOP) for sampling all types of produced water but, $3(37.5 \%)$ of the industries did not include validation frequency and sampling points in their sampling procedure. This could make the offline monitoring unreliable as the sampling may not be representative. The lack of online monitoring systems might result in parameters such as conductivity and other tests to peak high suddenly as stated by a respondent from the industry lacking online monitoring system. Furthermore, half of the industries $4(50.0 \%)$ reported that there was no automatic system to prevent use of water when it is Out Of Specification (OOS).

With regard to the WFI, the USP guidelines require a bacteria-count limit of $10 \mathrm{cfu} / 100 \mathrm{ml}$ (Paul, 2002). According to the results of this study, bacterial count limit for PW and WFI was to the standard for 5 (62.5\%) industries and they took in an investigation according to OOS when the action limit is exceeded. For WPU, there should be an automatic system to prevent use of water when it is OOS (Paul, 2002) but it was only applicable for $4(50 \%)$ of the pharmaceutical industries. However, if there is no automatic system, there will not be rejection of unfit water from the system which may result in end product of compromised quality. The WHO recommends appropriate sanitary specification plastics and stainless steel materials for WPU systems and when stainless steel is used, it should be at least grade $316 \mathrm{~L}$ (WHO, 2005). In this study it has been found that majority $(87.5 \%)$ of the industries comply with this specification.

\section{Validation, Documentation and Record Systems}

Validation and qualification of water treatment systems are fundamental parts of GMP and form an integral part of a GMP inspection. In addition, the validation activities should be documented and controlled through the use of qualification protocols and reports, typically these will fall into categories including installation qualification (IQ), operational qualification (OQ) and performance qualification (PQ). A three-phase approach should be used to satisfy the objective of proving the reliability and robustness of the system in service over an extended period (WHO, 2010).

According to the present study, $6(75.0 \%)$ of the industries performed IQ, OQ, and PQ. The proportion of industries practicing sampling record for phase I, phase II, and phase III validation were $5(62.5 \%), 3$ $(42.9 \%)$, and $2(25.0 \%)$, respectively. Industries 
performing phase I demonstrated that the system operates within predetermined operating ranges and delivers water of the required quality, and then develop SOP based on demonstration. Those performing phase II were using SOP developed during phase I for the water system. Those industries which were not performing phase III validation had no way of checking the system over long period of time which considers seasonal variation.

The result of validation summary records showed that the system was under control in $3(42.9 \%)$ industries and there was SOP development initiation during validation in $3(37.5 \%)$ of the industries among eight. Deviation from the designed criteria in qualifications and validation was investigated and corrective action was taken for deviation in only $1(12.5 \%)$ of the industries, but corrective action should be taken for every deviation from the designed criteria in qualifications and validation (Larsson et al. 1997). In addition to this, although documentation is a key part of validation system, only one of the industries developed report of investigation.

The results of this study showed that all of the industries had written procedures for the operation system of PW. This is an important aspect of documentation as SOPs are among the major documents required for proper function of the production system. The presence of written procedures for the operation system of PW and regeneration of IX resins were reported by all $8(100 \%)$ industries. There were also record keeping practices for all tests undertaken by all of the pharmaceutical industries. This would help in tracing back the monitoring and quality control practices of the industries during production of WPU.

The proportion of industries keeping records for all tests undertaken, for filter sanitization, filter replacement, chemical sanitization, and periodic integrity tests was found to be 8 (100\%), 1 (14.3\%), 4 (50.0\%), 4 (57.1\%), and $1(12.5 \%)$ respectively (Table 3$)$.

Table 3: Distribution of items indicating the validation processes and documentation and record systems of water treatment systems of the pharmaceutical manufacturing industries in Ethiopia, 2013 (N=8).

\begin{tabular}{|c|c|c|c|}
\hline \multirow{2}{*}{ Items } & \multicolumn{3}{|c|}{ Response } \\
\hline & Yes; N (\%) & No; N (\%) & $\mathbf{N A} ; \mathbf{N}(\%)$ \\
\hline Underwent IQ & $6(75)$ & $2(25)$ & - \\
\hline Qualification of water system installation & $5(62.5)$ & $3(37.5)$ & - \\
\hline Underwent OQ & $6(75)$ & $2(25)$ & - \\
\hline Underwent PQ & $6(75)$ & $2(25)$ & - \\
\hline $\begin{array}{l}\text { The result of validation summary records showing the system was } \\
\text { under control }\end{array}$ & $3(42.9)$ & $3(42.9)$ & $1(14.3)$ \\
\hline SOP development initiation during validation & $3(37.5)$ & $5(62.5)$ & - \\
\hline $\begin{array}{l}\text { Investigation of deviation from the designed criteria in qualifications } \\
\text { \&validation }\end{array}$ & $1(12.5)$ & $4(50)$ & $3(37.5)$ \\
\hline Corrective action taken for the deviation & $1(16.7)$ & $3(50)$ & $2(33.3)$ \\
\hline Report of investigation & $1(12.5)$ & $3(37.5)$ & $3(50)$ \\
\hline Documentation for all the tests undertaken & $8(100)$ & - & - \\
\hline Availability of written procedures for the operation of system of PW & $8(100)$ & - & - \\
\hline $\begin{array}{l}\text { Presence of a record of sanitization of carbon filter with validated } \\
\text { frequency }\end{array}$ & $1(14.3)$ & $5(71.4)$ & $1(14.3)$ \\
\hline Documentation being present for filter replacement & $4(50)$ & $3(37.5)$ & $1(12.5)$ \\
\hline Presence of $\mathrm{SOP}_{\mathrm{s}}$ for the regeneration of Ion exchange resins & $8(100)$ & - & - \\
\hline Records were kept for regeneration of ion exchange resins & $8(100)$ & - & - \\
\hline Records being kept for the chemical sanitization & $4(57.1)$ & - & $3(42.9)$ \\
\hline $\begin{array}{l}\text { Presence of a record for the sanitation of PW storage and } \\
\text { distribution system }\end{array}$ & $7(87.5)$ & $1(12.5)$ & $1(12.5)$ \\
\hline periodic integrity test records being kept & $1(12.5)$ & $3(37.5)$ & $4(50)$ \\
\hline
\end{tabular}

\section{Storage Practice and Distribution System}

The study showed that all $8(100 \%)$ of the pharmaceutical industries had a tank for PW storage while the presence of storage tanks for WFI was only 5 $(62.5 \%)$. Among the available storage tanks, 7 (87.5\%) of them were of a sanitary material (Table 4). With regard to the distribution system of the water treatment systems, 4 (50\%) industries had pipes which were not made of sanitary material, the PW was not kept circulating at $70-80{ }^{\circ} \mathrm{C}$ and there were dead legs in the water distribution lines and the temperature was not 
maintained at $70-80{ }^{\circ} \mathrm{C}$ in $4(50 \%)$ of the industries. This may disrupt quality of the water as stagnant waters with no circulations and water at low temperature are more susceptible to microbial proliferation (WHO,
2010). Moreover, the pipes used in the distribution of WFI were ensuring delivery of the water up to the point of use in $5(62.5 \%)$ industries (Table 4$)$.

Table 4: Distribution of items indicating the storage practices and distribution of water in pharmaceutical industries in Ethiopia, $2013(\mathrm{~N}=8)$.

\begin{tabular}{|l|c|c|c|}
\hline \multicolumn{1}{|l|}{ Items } & \multicolumn{2}{|c|}{ Response } \\
\cline { 2 - 4 } & Yes; N (\%) & No; N (\%) & NA; N (\%) \\
\hline Presence of a tank for PW storage & $8(100)$ & - & - \\
\hline A tank being type of sanitary material for PW & $7(87.5)$ & $1(12.5)$ & - \\
\hline Presence of a storage tank for water for injection & $5(62.5)$ & - & $3(37.5)$ \\
\hline Tank being made of sanitary material for WFI & $5(62.5)$ & - & $3(37.5)$ \\
\hline Maintenance of temperature at 70-80 ${ }^{\circ}$ during storage & $5(62.5)$ & - & $3(37.5)$ \\
\hline Presence of dead legs in the water system & $4(50)$ & $4(50)$ & - \\
\hline PW was kept circulating & $7(87.5)$ & $1(12.5)$ & - \\
\hline $\begin{array}{l}\text { Pipes used in the distribution of WFI were ensuring delivery of the } \\
\text { water up to the point of use }\end{array}$ & $5(62.5)$ & - & $3(37.5)$ \\
\hline Pipes were made of sanitary material & & $1(12.5)$ & $3(37.5)$ \\
\hline Water was maintained circulating at 70-80 ${ }^{\circ} \mathrm{C}$ & $4(50)$ & - & $4(50)$ \\
\hline
\end{tabular}

\section{Findings of Key Informant Interview}

A total of eight key informants from eight industries were interviewed using flexible interview guide. When they were asked on overall compliance of the water treatment systems of the pharmaceutical industries to the WHO GMP principles, majority of the respondents mentioned that their water treatment system fulfills most of the GMP requirements. On the contrary, one of the participants explained the status of an industry as follows:

"...the existing system is an old model which is way behind the current GMP requirement. Qualification is not done yet for the existing system."

Regarding the challenges encountered and actions taken during the purification, storage, and distribution of WPU, shortage of raw water supply was the major challenge mentioned by majority of the participants. As a result, different measures were taken by different industries including using one's own groundwater source, installation of internal pump and using large volume reservoirs. Other challenges stated by some of the respondents were increased conductivity of source water, decreased adsorption capacity, increased concentration of $\mathrm{NaOH}$ used for regeneration of IX resin, absence of online monitoring system and loop circulation system. In some of the pharmaceutical industries these resulted in deviation of some parameters and failure of microbiological tests. However, according to the respondents, appropriate actions were taken to resolve some of these challenges. This was evident from one of the respondents:
"The problem of increased conductivity was resolved by enhancing the efficiency of the demineralizer and galvanization of the water line from the well up to the raw water storage tank while decreased adsorption capacity of the carbon filter was resolved by changing the carbon filter and regeneration of IX resin."

Participants were asked to mention the opportunities and threats towards implementation of the GMP principles for water system. Accordingly, the support of the government was mentioned by most of the participants to be the main opportunity for the industries. These include giving local manufacturers priority on the market and allowing tax free imports of raw materials and machineries. Further, training program from the FMHACA and other organizations like GIZ (German Federal Enterprise for International Cooperation) were mentioned as opportunities. On the other hand, the study participants revealed that erratic raw water supply, absence of competent calibration laboratories, shortage of foreign currency, and delay during import of raw materials and equipment were among the main threats for the pharmaceutical industries in Ethiopia.

Finally, participants were asked about their recommendations and they suggested, among others, continuous training and technical support from different stakeholders like FMHACA and professional associations, implementation of tighter control by regulatory bodies, and stronger University-Industry linkages to facilitate training and research \& development collaborations. 


\section{CONCLUSION}

According to the results of the study, it has been found that the water treatment systems in most of the pharmaceutical industries do not fully comply with the GMP specifications. With regard to monitoring system, almost all the pharmaceutical industries have online and offline monitoring systems during production of WPU. The storage systems for PW and WFI comply with the WHO GMP principles for most of the pharmaceutical industries. Similarly, the documentation practice of most of the industries was found to be close to the standard. On the other hand, the distribution systems of some industries did not ensure continuous circulation and maintenance of temperature at $70-80{ }^{\circ} \mathrm{C}$ and the validation process in most of the industries was found to be poor with respect to the standard. Finally, most of the industries indicated that shortage of raw water supply, absence of competent calibration laboratories, and longer lead time during import of raw materials were some of the limiting factors in fulfilling the GMP standards.

\section{REFERENCES}

1. Agalloco J, Akers J (2008), Sterile Product Manufacturing. In: Gad SC ed., Pharmaceutical Manufacturing Handbook: Production and Processes. John Wiley \& Sons, Hoboken, New Jersey, pp. 99-135.

2. European Medicines Evaluation Agency (EMEA) (2003), Good Manufacturing Practices, Chapter 4: Building and facilities, EMEA, London.

3. Food, Medicines and Health Care Administration and Control Authority (FMHACA) (2012). Good Manufacturing Practice guidelines for pharmaceutical products, Addis Ababa, Ethiopia.

4. Gronwald M, Gomez R. (2012). Generation of Pharmaceutical Water. In: Pharmaceutical Water. Maas and Peither AG - GMP Publishing, Germany, pp.1-10

5. Khutia AR, Panda DS, Jena AK, Panda SP, Nayak MR (2010). Validation of Water Purification System for Pharmaceuticals. Int J Pharm Tech Res 2: 1395-1397.

6. Larsson G, Anderson R, Egan A (1997). A WHO Guide to Good Manufacturing Practice (GMP) Requirements, WHO, Geneva, p 1112. Available at: http://whqlibdoc.who. int/h q/1997/WHO VSQ 97.02.pdf. [Accessed on: 1 May 2013].

7. Nally JD (2007). Good Manufacturing Practices for Pharmaceuticals, $6^{\text {th }}$ edn, Nallianco LLC, USA, p 1-3.

8. Pahwa R, Piplani M, Sharma PC, Nanda A (2010). Validation Aspects of Water Treatment Systems for Pharmaceutical Products. Trop J Pharm Res, 9: 81

9. Paul DH (2002). Electrodeionization in Pharmaceutical Water Treatment, David H. Paul Inc., Farmington, New Mexico, pp. 36-42.

10. Veolia Water Solutions and Technologies (VWS) (2005). Pharmaceutical pure water guide. Available at: http://www.pharma.veoliawaterst.com/pcc/ressources/documents/1/4680,9308 A1PCCPHARMPWGuideV3FINAL.pdf. [Accessed on: 20 April 2013].

11. WHO (2010). Good manufacturing practices for active pharmaceutical ingredients. Forty-fourth Report of a WHO Expert Committee on Specifications for Pharmaceutical Preparations. World Health Organization Technical Report Series, World Health Organization, Geneva.

12. WHO (2006). Supplementary guidelines on good manufacturing practices (GMP): Validation. Fortieth report WHO expert committee on specifications for pharmaceutical preparations. World Health Organization, Geneva.

13. WHO (2005). WHO Good Manufacturing Practices: water for pharmaceutical use. World Health Organization, Geneva.

14. WHO (2003). Good Manufacturing Practices For Pharmaceutical Products: main principles. Thirty-seventh report of a WHO Expert Committee on Specifications for Pharmaceutical Preparations. World Health Organization Technical Report Series. World Health Organization, Geneva.

15. WHO (1997). A WHO guide to good manufacturing practice (GMP) requirements Part 2: Validation. World Health Organization, Geneva.

16. Ziegler IM, Medgyesi I (2012). Increased importance of the documented development stage in process validation. Saudi Pharm J 20: $283-285$. 


\section{This page intentionally left blanked}

